Research Article

\title{
Experimental Study on Physical and Dynamic Mechanical Properties of Temperature-Water Coupled Sandstone
}

\author{
Qi Ping $\mathbb{D}^{1,2,3}$ Dezhi Qi, ${ }^{2,3}$ Qi Diao, ${ }^{2,3}$ Chuanliang Zhang, ${ }^{2,3}$ Qi Gao, ${ }^{2,3}$ and Yulin Wu ${ }^{2,3}$ \\ ${ }^{1}$ State Key Laboratory of Mining Response and Disaster Prevention and Control in Deep Coal Mine, \\ Anhui University of Science and Technology, Huainan, Anhui 232001, China \\ ${ }^{2}$ Engineering Research Center of Mine Underground Projects, Ministry of Education, Anhui University of Science and Technology, \\ Huainan, Anhui 232001, China \\ ${ }^{3}$ School of Civil Engineering and Architecture, Anhui University of Science and Technology, Huainan, Anhui 232001, China
}

Correspondence should be addressed to Qi Ping; ahpingqi@163.com

Received 22 April 2021; Accepted 8 July 2021; Published 3 August 2021

Academic Editor: Bangbiao Wu

Copyright (C) 2021 Qi Ping et al. This is an open access article distributed under the Creative Commons Attribution License, which permits unrestricted use, distribution, and reproduction in any medium, provided the original work is properly cited.

In order to study the influence characteristics of water bath at different temperatures on rock physical and dynamic mechanical properties, a total of 15 groups of temperature-water bath treatment were carried out on coal mine roadway sandstone at $25^{\circ} \mathrm{C} \sim 95^{\circ} \mathrm{C}$, and the basic physical parameters were tested. The impact compression test was carried out using the split Hopkinson pressure bar (SHPB) device. The results show that, with the increase of water bath temperature, the particle gap on the specimen surface increases. The volume, mass, and density of the specimens all increased with the increase of water bath temperature, and the increase was closely related to the water bath temperature. The dynamic compressive strength increases as a quadratic function of the water bath temperature, and the rate of increase is different before and after $45^{\circ} \mathrm{C}$. The dynamic peak strain and average strain rate showed a quadratic function with the water bath temperature. The dynamic peak strain before $45^{\circ} \mathrm{C}$ decreased with the temperature increasing, and the dynamic peak strain after $45^{\circ} \mathrm{C}$ increased with the temperature increasing. The dynamic elastic modulus increased first and then decreased with the increase of water bath temperature and reached the maximum at $45^{\circ} \mathrm{C}$. The failure pattern of sandstone is spalling. With the increase of water bath temperature, the fracture degree of the specimen gradually decreases.

\section{Introduction}

In recent years, with increasing excavation depth of underground space, the ground temperature is also getting higher [1]. Deep rock mass excavation is often in a special environment full of water [2]. Blasting excavation is one of the main excavation methods of deep rock mass engineering. Deep rock mass is subjected to impact load during excavation. Underground rock mass is mostly in the state of immersion, and different depth corresponding to the water temperature is different. Therefore, it is of great engineering value to carry out the experimental study on the dynamic mechanical properties of sandstone under the coupled action of temperature and water.

Many scholars have used TAW-2000 or RMT-150B rock mechanics test system to carry out static load test research on rocks under or after high-temperature treatment. Qin et al. [3] carried out uniaxial compression tests on sandstone specimens treated at $200^{\circ} \mathrm{C}$ to $800^{\circ} \mathrm{C}$ and analyzed its stressstrain curve characteristics. Yu et al. [4] studied the variation characteristics of mass and longitudinal wave velocity with temperature after limestone was subjected to a high temperature of $20^{\circ} \mathrm{C}$ to $650^{\circ} \mathrm{C}$ and carried out uniaxial compression tests under static load. Jin et al. [5] compared two ways of natural cooling and water cooling after sandstone was subjected to a high temperature of $100^{\circ} \mathrm{C}$ to $800^{\circ} \mathrm{C}$. Wu and Wang [6] carried out uniaxial compression and Brazil splitting tests on granites subjected to a high temperature of $250^{\circ} \mathrm{C}$ to $600^{\circ} \mathrm{C}$, to analyze the stress-strain curve and loadradial displacement curve of granites. Rohan et al. [7] studied the effects of pretreatment on UPV and rock microstructure after treated at $100^{\circ} \mathrm{C}$ to $600^{\circ} \mathrm{C}$. Yu et al. [8] 
conducted uniaxial compression tests on sandstone after high-temperature treatment at $100^{\circ} \mathrm{C}$ to $600^{\circ} \mathrm{C}$ and under a high-temperature condition and analyzed the uniaxial compressive strength of sandstone after high-temperature cooling and under high-temperature condition. Su et al. [9] used the RMT-150B testing machine to analyze the deformation characteristics, strength characteristics, and acoustic emission characteristics of hard coal samples treated at $100^{\circ} \mathrm{C}$ to $500^{\circ} \mathrm{C}$. Wei et al. [10] carried out static uniaxial compression on anthracite samples after hightemperature treatment at $20^{\circ} \mathrm{C}$ to $500^{\circ} \mathrm{C}$ and analyzed the change of coal sample density and porosity with temperature. Chen et al. [11] carried out uniaxial compression tests on granite specimens under a high temperature of $25^{\circ} \mathrm{C}$ to $1000^{\circ} \mathrm{C}$ at five loading rates. Split Hopkinson pressure bar (SHPB) device is the most commonly used loading device in the study of rock dynamic physical and mechanical properties. Ping et al. [12-15] analyzed the variation rule of the dynamic stress-strain curve of sandstone under a high temperature of $25^{\circ} \mathrm{C}$ to $1000^{\circ} \mathrm{C}$. In addition, the effects of temperature on dynamic compressive strength, dynamic peak strain and strain rate, dynamic elastic modulus, and failure mode were investigated. Xu et al. [16] carried out dynamic uniaxial compression tests at three loading rates on sandstone subjected to a high temperature ranging from $25^{\circ} \mathrm{C}$ to $700^{\circ} \mathrm{C}$. Zhang [17] analyzed the variation of dynamic stress, strain, strain rate, fractal dimension, failure mode, and damage degree with a temperature of sandstone subjected from $-15^{\circ} \mathrm{C}$ to $800^{\circ} \mathrm{C}$. Chen et al. [18] carried out a dynamic uniaxial compression test on sandstone subjected to a high temperature of $100^{\circ} \mathrm{C}$ to $1000^{\circ} \mathrm{C}$. Liu and $\mathrm{Xu}$ [19] carried out dynamic compression tests on granite under a high-temperature action of $25^{\circ} \mathrm{C}$ to $1000^{\circ} \mathrm{C}$ and analyzed the variation law of peak stress and strain of granite with temperature. Yang et al. [20] conducted triaxial compression tests on granites subjected to a high temperature of $200^{\circ} \mathrm{C} \sim 800^{\circ} \mathrm{C}$ and found that thermal cracks were generated and the cohesion between crystals was reduced.

Scholars at home and abroad mainly focus on the static and dynamic physical and mechanical properties of rocks in water. Xie et al. [21] used MTS815 testing machine to conduct uniaxial and triaxial compression tests on red-bed soft rocks under natural and saturated conditions and analyzed its strength and deformation characteristics. Liu et al. [22] used Rock-600-50 triaxial rheometer to analyze the mechanical behavior and energy evolution rule of yellow sandstone under the action of pore water. Duan and Ren [23] carried out static uniaxial compression tests on five kinds of sandstone with different water contents and analyzed the law of various physical parameters changing with water content. Zhang et al. [24] carried out a uniaxial compression acoustic emission test on saturated granite. Fang et al. [25] conducted uniaxial compression tests on four kinds of argillaceous siltstones and discussed the strength damage evolution characteristics of argillaceous siltstones under the influence of water content. Teng et al. [26] carried out uniaxial compression tests on four kinds of layered shales with water content and analyzed that the damage of water to shale was mainly due to adsorption of water and capillary pressure. Su et al. [27] carried out uniaxial compression tests on natural and saturated sandstone and analyzed the deformation, strength, and energy characteristics of the specimens. Zhang [28] analyzed the water-rock interaction of shale and obtained the microscopic nature of the deterioration of water-rock interaction of shale. Fu et al. [29] carried out uniaxial compression tests on rock samples under natural state, saturated water action, and dry-wet cycle, to analyze the uniaxial compressive strength and elastic modulus of sandstone. Yang et al. [30] carried out uniaxial compression tests on siltstone samples soaked in water at $50^{\circ} \mathrm{C}$ and $100^{\circ} \mathrm{C}$ and discussed the infrared radiation characteristics of siltstone in the rupture process soaked at different water temperatures. Gao et al. [31] carried out uniaxial dynamic compression loading tests on marble under four damage gradients and dry and saturated states, to analyze the relationship between dynamic compressive strength and water content. Wang et al. [32] carried out a uniaxial dynamic compression test and dynamic splitting test on fine sandstone in a natural and saturated state and analyzed the effects of water and loading rate on dynamic tensile and compressive strength of fine sandstone and their differences. Zhao et al. [33] carried out dynamic tensile tests on sandstone specimens with different water contents and studied the variation rule of dynamic tensile strength of sandstone specimens with different water content under different loading rates. Zhou et al. [34] carried out dynamic compression, splitting, and fracture tests on dry and saturated sandstone and analyzed the relationship between rock strength and fracture toughness with water and loading rate. Chu et al. [35] carried out uniaxial dynamic compression tests on sandstone samples with three different waterbearing states and analyzed the stress-strain curves of the rock samples. Wang et al. [36] conducted uniaxial dynamic compression tests on four kinds of red sandstone with different water-bearing states and analyzed the rock failure micromechanism. Guo et al. [37] conducted an experimental study on the thermal conductivity of sandstone at different temperatures and water content and found that the thermal conductivity of sandstone in a saturated state decreased with the increase of temperature. Yu et al. [38] conducted uniaxial compression mechanical tests on granite after hydrothermal cycling and analyzed its appearance morphology and stressstrain curve. Hashiba and Fukui [39] carried out tensile tests on five kinds of rocks and found that the strength of rocks decreases after being saturated with water. Wong and Jong [40] studied the effect of water on the tensile strength of gypsum and found that water can reduce the tensile strength of gypsum. Karakul and Ulusay [41] conducted tensile tests on rock and found that the tensile strength of rocks decreased with the increase of water saturation. An et al. [42] carried out experimental research on rocks under the coupling action of high temperature and dynamic load, carried out dynamic and static tests on rocks, and obtained the relationship curves among loading rate, strain, temperature, compressive strength, and tensile strength. Wen et al. [43] conducted a dynamic compressive test study on sandstone under the coupling action of low temperature and dynamic load, analyzed the fracture morphology 
characteristics, and obtained the dynamic failure law of sandstone. Wang et al. [44] conducted dynamic compression tests on Huashan granite to study the effects of treatment temperature and strain rate on the mechanical behavior of granite.

It can be seen that there are many researches on the static and dynamic physical and mechanical properties of sandstone under the action of high temperature and water rock. The researches on the physical and mechanical properties of sandstone under the action of temperature-water coupling mainly focus on the static load test, while the dynamic load test needs to be further studied. For studying physical and dynamic mechanical properties of sandstone is influenced by temperature and water coupling rules, the basic physical parameters of sandstone specimens after water bath at $25^{\circ} \mathrm{C}$, $30^{\circ} \mathrm{C}, 35^{\circ} \mathrm{C}, 40^{\circ} \mathrm{C}, 45^{\circ} \mathrm{C}, 50^{\circ} \mathrm{C}, 55^{\circ} \mathrm{C}, 60^{\circ} \mathrm{C}, 65^{\circ} \mathrm{C}, 70^{\circ} \mathrm{C}, 75^{\circ} \mathrm{C}$, $80^{\circ} \mathrm{C}, 85^{\circ} \mathrm{C}, 90^{\circ} \mathrm{C}$, and $95^{\circ} \mathrm{C}$ were measured, and the color, mass, volume, and density of the specimens were compared and analyzed. The impact compression tests of sandstone specimens subjected to different water bath temperatures were carried out under similar loading conditions by using SHPB equipment. The correlation between dynamic characteristics of the specimens, such as peak stress strength, dynamic elastic modulus, average strain rate, and failure mode, and the change of water bath temperature was studied.

\section{Sample Preparation and SHPB Test Device after Water Bath}

2.1. Processing of Sandstone Specimen. Rock specimens used in this test are all taken from the deep roadway sandstone of Gubei Coal Mine of Huainan Mining Group in Anhui Province. In order to increase the contrast between the test specimens, the test specimens are all selected from the same rock block. According to the relevant provisions of "Methods for Determination of Physical and Mechanical Properties of Coal and Rock" [45], rock coring machine, cutting machine, and end grinding machine were used to grind the specimen into a cylinder specimen with a diameter of $50 \mathrm{~mm}$ and a length-diameter ratio of about 0.5 .

\subsection{Preparation of Specimens after Water Bath. The box-type} water bath box is used to heat the sandstone specimen in the water bath, as shown in Figure 1. The size of the box is $420 \mathrm{~mm} \times 200 \mathrm{~mm} \times 105 \mathrm{~mm}$, and the maximum heating temperature is $99^{\circ} \mathrm{C}$.

First of all, the sandstone test pieces are evenly placed in the water bath box, with a certain gap between the test pieces and the door of the box closed. After heating to the corresponding temperature, keep the temperature with a con-

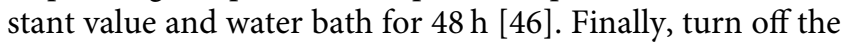
water bath heating system, open the box cover, remove the specimen from the water bath box, wipe the moisture on the surface of the specimen with a dry towel, and measure the mass, diameter, thickness, and longitudinal wave velocity of the specimen.

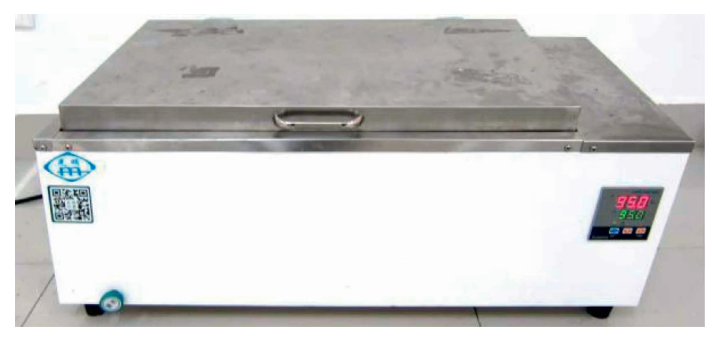

Figure 1: Water bath.

2.3. SHPB Test Device. The test equipment in this paper is the SHPB test device of the State Key Laboratory of Mining Response and Disaster Prevention and Control in Deep Coal Mine, as shown in Figure 2. The impact compression test is carried out on sandstone specimens subjected to different water bath temperatures.

The SHPB test device shown in Figure 2 is mainly composed of an impact bar, an incident bar, a transmission bar, an absorbing bar, an oscilloscope, and a CS dynamic resistance strain gauge. The diameter of the incident bar, transmission bar, and absorption bar is $50 \mathrm{~mm}$, bar length is $2000 \mathrm{~mm}, 1500 \mathrm{~mm}$, and $1000 \mathrm{~mm}$, respectively, with a material density of $7636 \mathrm{~kg} / \mathrm{m}^{3}$, Poisson ratio is 0.28 , elastic longitudinal wave velocity is $5190 \mathrm{~m} / \mathrm{s}$, and the impact rod adopts spindle shape. Before installation, a thin layer of Vaseline is evenly applied to the contact area between the pressure bar and the end face of the specimen as a lubricant to reduce the friction between the sandstone specimen and the end face of the pressure bar. In order to compare the influence law of water bath action at different temperatures on the dynamic characteristics of sandstone specimens, it is necessary to ensure the same impact loading conditions for each impact compression test in SHPB; that is, the same impact pressure is used to load specimens. The experimental principle is to measure the incident wave and reflected wave in the incident bar and the transmitted pulse in the transmission bar by using a strain gauge and obtain the stress-strain relationship according to the stress wave theory [47].

\section{Physical Properties of Sandstone before and after Water Bath}

3.1. Color and Apparent Morphology of Specimens after Water Bath. The color and apparent morphological changes of sandstone specimens subjected to different water bath temperatures are shown in Figure 3.

As can be seen from Figure 3, the surface color of sandstone specimens after water bath at $25^{\circ} \mathrm{C} \sim 95^{\circ} \mathrm{C}$ did not change significantly and was mainly grayish-white. After water bath at $25^{\circ} \mathrm{C} \sim 45^{\circ} \mathrm{C}$, the particles on the surface of sandstone are dense. After water bath at $45^{\circ} \mathrm{C} \sim 95^{\circ} \mathrm{C}$, the particle gap on the surface of the specimen increases. It can be inferred that, with the increase of temperature, water gradually enters the specimen through the cracks on the surface, and water molecules weaken the binding effect between mineral particles and promote the particles to fall off, thus increasing the pores of sandstone. This indicates 


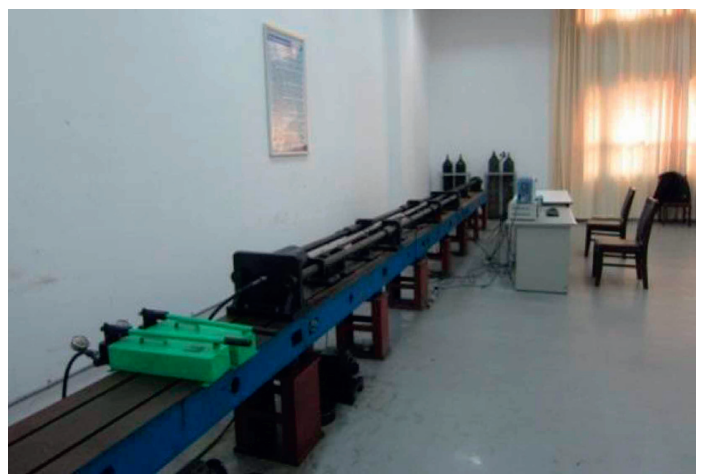

Figure 2: SHPB test device.

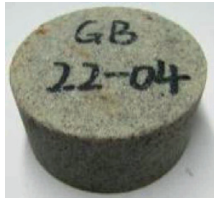

(a)

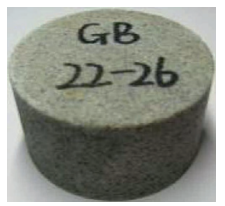

(f)

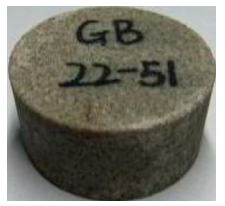

(k)

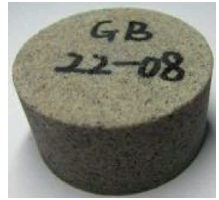

(b)

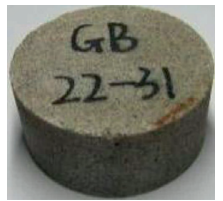

(g)

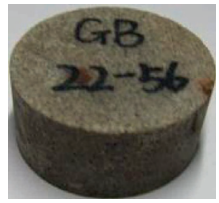

(1)

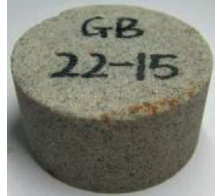

(c)

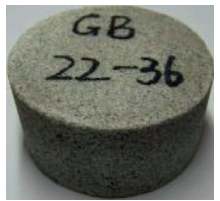

(h)

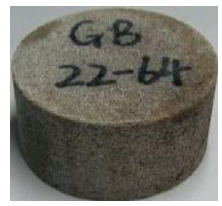

(m)

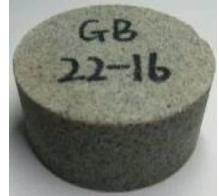

(d)

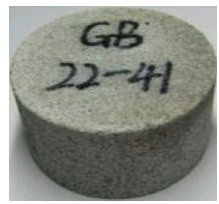

(i)

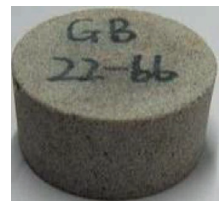

(n)

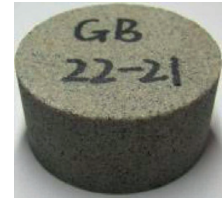

(e)

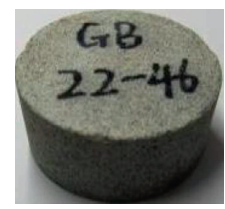

(j)

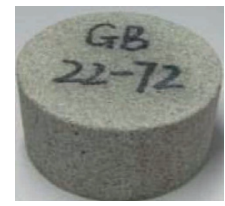

(o)

Figure 3: Apparent morphology of sandstone specimens after water bath at different temperatures. (a) $25^{\circ} \mathrm{C}$. (b) $30^{\circ} \mathrm{C}$. (c) $35^{\circ} \mathrm{C}$. (d) $40^{\circ} \mathrm{C}$. (e) $45^{\circ} \mathrm{C}$. (f) $50^{\circ} \mathrm{C}$. (g) $55^{\circ} \mathrm{C}$. (h) $60^{\circ} \mathrm{C}$. (i) $65^{\circ} \mathrm{C}$. (j) $70^{\circ} \mathrm{C}$. (k) $75^{\circ} \mathrm{C}$. (l) $80^{\circ} \mathrm{C}$. (m) $85^{\circ} \mathrm{C}$. (n) $90^{\circ} \mathrm{C}$. (o) $95^{\circ} \mathrm{C}$.

that when the temperature is between $25^{\circ} \mathrm{C}$ and $45^{\circ} \mathrm{C}$, a small amount of water enters the interior of the sandstone, and the internal structure of the sandstone specimen is mainly the combination between particles. After $45^{\circ} \mathrm{C}$, more water enters the sandstone, and the internal structure of sandstone specimen is mainly composed of a water-particle combination.

3.2. Measurement and Results of Basic Physical Parameters. After the specimen taken out of the water bath box is wiped clean with a dry towel, the size and mass of the sandstone specimen are measured one by one, and the volume and density are calculated. The C61 nonmetallic ultrasonic detector was used to measure the elastic wave propagation time between the two end faces of the specimen, and longitudinal wave velocity was calculated. The basic physical parameters of sandstone specimens before and after water bath are shown in Table 1.
3.3. Changes in Volume, Mass, and Density of Specimens. After water bath at different temperatures, the sandstone specimens showed volume expansion and mass increase, and the volume expansion rate increased with the increase of water bath temperature, as shown in Figure 4.

As can be seen from Figure 4, the volume expansion rate of sandstone specimen was not affected by the change of water bath temperature in the range of $25^{\circ} \mathrm{C} \sim 45^{\circ} \mathrm{C}$, and the increased value varied from $0.39 \%$ to $0.45 \%$. The volume expansion rate showed a slight increase, and the volume expansion rate was the smallest at $25^{\circ} \mathrm{C}$, only $0.39 \%$. This may be because the water bath caused the volume expansion of the mineral particles composed of sandstone, which first occupied the original micropores and microcracks in the specimen, so the volume expansion of the specimen was relatively small. When the water bath temperature rose to $45^{\circ} \mathrm{C}$, new microcracks sprouted inside the sandstone specimen, leading to the appearance volume expansion of the specimen, and the volume expansion rate increased 


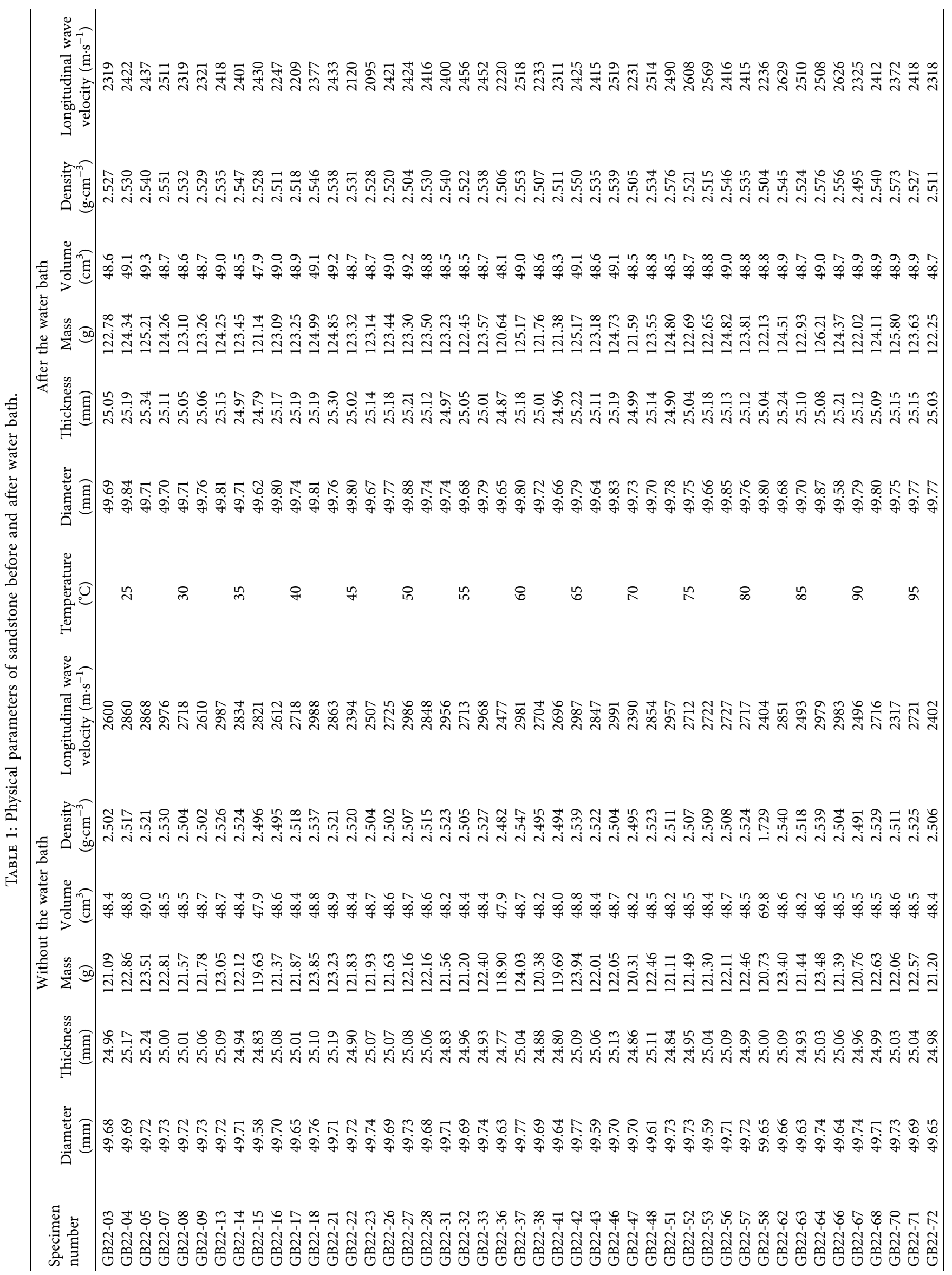


rapidly. When the water bath temperature was increased to $95^{\circ} \mathrm{C}$, the volume expansion rate of the specimen reached the maximum of $0.94 \%$.
The volume expansion rate of the sandstone specimen increases with the water bath temperature in a quadratic function relationship, as shown in equation (1), and the fitting curve is shown in Figure 4:

$$
\begin{cases}V_{T 1}^{\prime}=9 \times 10^{-5} T^{2}-0.003 T+0.4117,25^{\circ} \mathrm{C} \sim 45^{\circ} \mathrm{C}, & R^{2}=0.9975 \\ V_{T 1}^{\prime}=9 \times 10^{-5} T^{2}-0.003 T+0.4117,45^{\circ} \mathrm{C} \sim 95^{\circ} \mathrm{C}, & R^{2}=0.9843\end{cases}
$$

where $V_{T 1}^{\prime}$ and $V_{T 2}^{\prime}$ are the volume expansion rate of sandstone specimen after water bath action, $\%$.

The variation of the water absorption rate of sandstone specimens with the rise of water bath temperature after water bath action is shown in Figure 5 .

As can be seen from Figure 5, the water absorption rate of specimens with different water bath temperatures increased with the increase of water bath temperature. With the increase of water bath temperature, the water absorption capacity of sandstone becomes stronger. Sandstone is mainly cemented by sand grains, which have more sand content, thus showing a temperature effect. The higher the temperature is, the easier the water will enter the interior of the sandstone. The relationship between water absorption of sandstone specimens and water temperature increases with a strong quadratic function after different water bath temperatures. As shown in equation (2), the fitting curve is shown in Figure 5:

$$
\begin{cases}M_{T 1}=4 \times 10^{-4} T^{2}-0.0224 T+1.514,25^{\circ} \mathrm{C} \sim 45^{\circ} \mathrm{C}, & R^{2}=0.9830 \\ M_{T 2}=5 \times 10^{-5} T^{2}+0.0176 T+0.4376,45^{\circ} \mathrm{C} \sim 95^{\circ} \mathrm{C}, & R^{2}=0.9820\end{cases}
$$

where $M_{T 1}$ and $M_{T 2}$ are the water absorption rate of sandstone specimen after water bath action, $\%$.

After the water bath, the density of sandstone specimen changes with the rise of water bath temperature, as shown in Figure 6.

It can be seen from Figure 6 that the density of the specimen increases with the increase of water bath temperature after the action of different water bath temperatures. When the water bath temperature was in the range of $25^{\circ} \mathrm{C} \sim 45^{\circ} \mathrm{C}$, the increase rate of the specimen density was less affected by the change of the water bath temperature, and the amplitude of the increase rate of the specimen density was
$0.51 \% \sim 0.68 \%$. When the water bath temperature was in the range of $45^{\circ} \mathrm{C}$ to $95^{\circ} \mathrm{C}$, the density of the specimen was greatly affected by the water bath temperature. The density increase rate at $45^{\circ} \mathrm{C}$ was $0.68 \%$, and the density increase rate at $95^{\circ} \mathrm{C}$ was the largest $(2.47 \%)$, which was about 3.6 times that at $45^{\circ} \mathrm{C}$. The basic reason for the increase of density of sandstone specimen is that the volume expansion and mass increase of sandstone specimen after water bath.

The density increase rate of sandstone specimen increases in a quadratic function between $25^{\circ} \mathrm{C}$ and $95^{\circ} \mathrm{C}$, and the growth rate is different before and after $45^{\circ} \mathrm{C}$, as shown in equation (3). The fitting curve is shown in Figure 6:

$$
\begin{cases}\rho_{T 1}=-6 \times 10^{-5} T^{2}+0.012 T+0.2489,25^{\circ} \mathrm{C} \sim 45^{\circ} \mathrm{C}, & R^{2}=0.9703 \\ \rho_{T 2}=4 \times 10^{-4} T^{2}-0.0288 T+1.0747,45^{\circ} \mathrm{C} \sim 95^{\circ} \mathrm{C}, & R^{2}=0.9693\end{cases}
$$

where $\rho_{T 1}$ and $\rho_{T 1}$ are the density increase rate of sandstone specimen after water bath action, $\%$.

\section{Test Results and Analysis of Sandstone with Different Water Bath Temperatures}

\subsection{Analysis of the Relationship between Different Water Bath} Temperatures and Peak Stress Strength. The variation of peak stress strength of sandstone specimens after water bath is shown in Figure 7.

It can be seen from Figure 7 that the dynamic peak stresses of sandstone specimen quadratic increase with the increase of water bath temperature between $25^{\circ} \mathrm{C}$ and $45^{\circ} \mathrm{C}$.
The absorb water ratio of sandstone specimen increases with increasing bath temperature, which resists the extension of cracks. Therefore, the peak stress increases accordingly. The peak stress strength increases rapidly between $45^{\circ} \mathrm{C}$ and $95^{\circ} \mathrm{C}$. It can be inferred that, with the increase of temperature, a certain amount of moisture and thermal stress accumulates inside the sandstone, and under the action of temperaturewater coupling, the internal pores of the sandstone are filled, thus improving the compressive strength of the sandstone.

The peak stress strength of sandstone specimens increases as a quadratic function with the water bath temperature, as shown in equation (4), and the fitting curve is shown in Figure 7: 


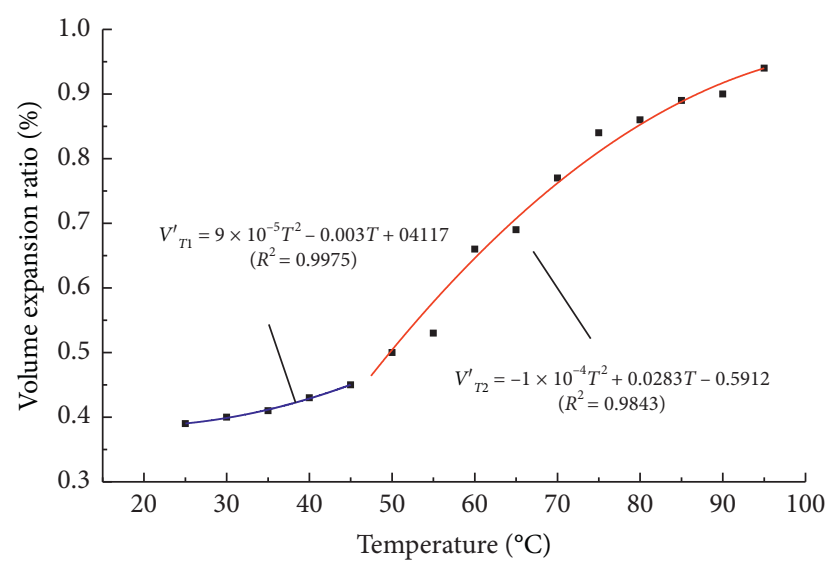

- Test date

- Fitted curve $25^{\circ} \mathrm{C} \sim 45^{\circ} \mathrm{C}$

- Fitted curve $45^{\circ} \mathrm{C} \sim 95^{\circ} \mathrm{C}$

Figure 4: Volume changes with water bath temperature.

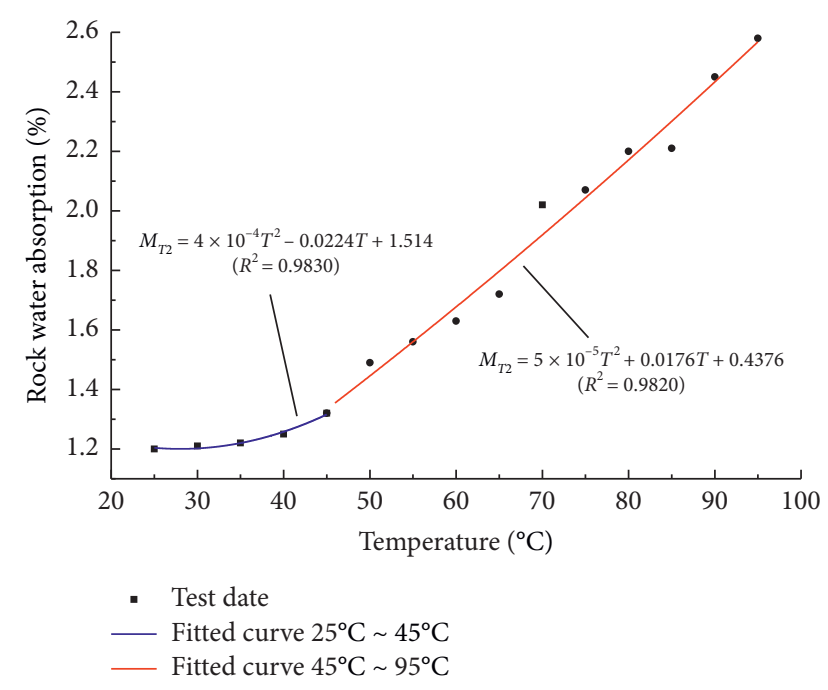

FIGURE 5: Relationship between water absorption of sandstone and water bath temperature.

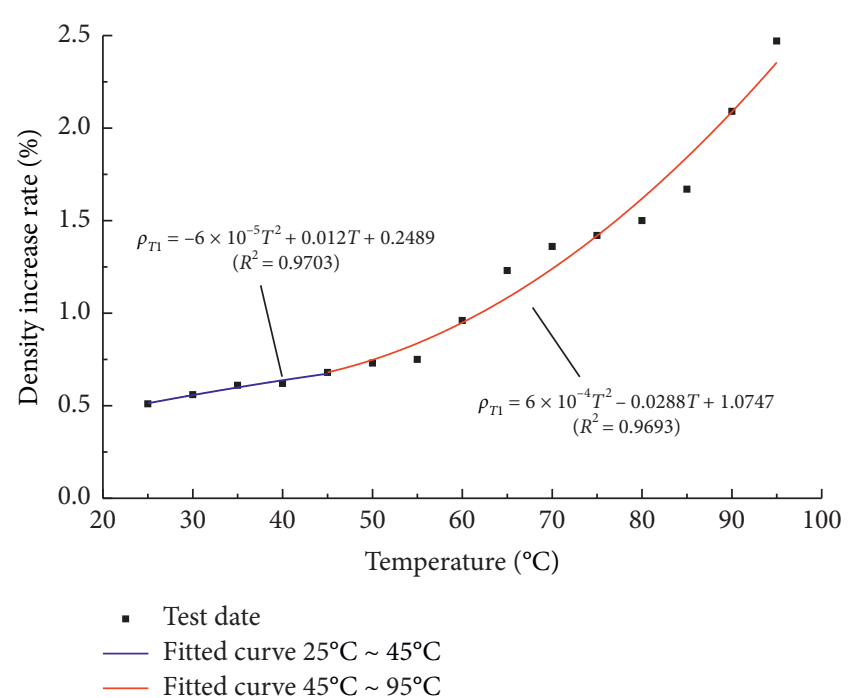

FIGURE 6: Density changes with water bath temperature.

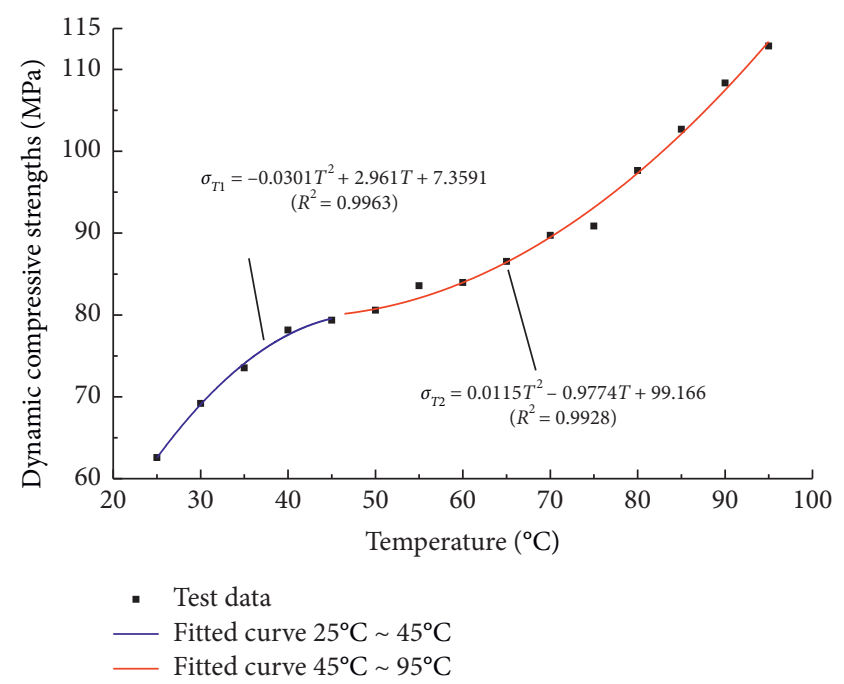

FIGURE 7: Fitting curve between water bath temperature and peak stress strength.

$$
\begin{cases}\sigma_{T 1}=-0.0301 T^{2}+2.961 T+7.3591,25^{\circ} \mathrm{C} \sim 45^{\circ} \mathrm{C}, & R^{2}=0.9963 \\ \sigma_{T 2}=0.0115 T^{2}-0.9774 T+99.166,45^{\circ} \mathrm{C} \sim 95^{\circ} \mathrm{C}, & R^{2}=0.9928\end{cases}
$$

where $\sigma_{T 1}$ and $\sigma_{T 2}$ are the peak stress strength of sandstone specimen after water bath action, MPa.

\subsection{Analysis of the Relationship between Different Water Bath} Temperatures and Peak Strain. The variation of peak strain of sandstone specimen with water bath temperature after water bath is shown in Figure 8.

It can be seen from the Figure 8 , The peak strain of sandstone specimen decreases at, $25^{\circ} \mathrm{C} \sim 45^{\circ} \mathrm{C}$. The sandstone specimen move the peak strain decreases with water bath temperature, and can be speculated that with the increase of bath temperature, sandstone specimens gathered a certain amount of internal thermal stress and water, and water under the action of thermal stress in these, the internal microcracks, filled with rock to produce thermal damage, the sandstone specimen of peak strain showed a trend of decrease. In the temperature range of $45^{\circ} \mathrm{C}$ water bath, the dynamic peak strain has little change, and the strain amplitude is $1.35 \times 10^{-3} \sim 2.27 \times 10^{-3}$. When the water bath 
temperature exceeds $45^{\circ} \mathrm{C}$, the dynamic peak strain obviously increases with the increase of the water bath temperature. When the temperature of the water bath reaches $95^{\circ} \mathrm{C}$, the dynamic peak strain is $5.23 \times 10^{-3}$, which is about 3.9 times compared with that at $45^{\circ} \mathrm{C}$.
The relationship between the dynamic peak strain of sandstone specimen and the water bath temperature is a quadratic function, as shown in equation (5), and the fitting curve is shown in Figure 8:

$$
\begin{cases}\varepsilon_{T 1}=0.0026 T^{2}-0.2238 T+6.198,25^{\circ} \mathrm{C} \sim 45^{\circ} \mathrm{C}, & R^{2}=0.9657 \\ \varepsilon_{T 2}=0.0015 T^{2}-0.1445 T+4.9419,45^{\circ} \mathrm{C} \sim 95^{\circ} \mathrm{C}, & R^{2}=0.9803\end{cases}
$$

where $\varepsilon_{T 1}$ and $\varepsilon_{T 2}$ are the dynamic peak strain of sandstone specimen after water bath action.

\subsection{Analysis of the Relationship between Different Water Bath} Temperatures and Dynamic Elastic Modulus. After the water bath, the dynamic elastic modulus of sandstone specimen changes with water bath temperature, as shown in Figure 9.

It can be seen from Figure 9 that the dynamic modulus of elasticity increases with the increase of water bath temperature between $25^{\circ} \mathrm{C}$ and $45^{\circ} \mathrm{C}$. The dynamic modulus of elasticity is $27.61 \mathrm{GPa}$ at $25^{\circ} \mathrm{C}$ and $79.36 \mathrm{GPa}$ at $45^{\circ} \mathrm{C}$, which is $187 \%$ higher than that at $25^{\circ} \mathrm{C}$. It reaches the peak value at $45^{\circ} \mathrm{C}$ and then decreases with the increase of water bath temperature. This is because when the water bath temperature is lower than $45^{\circ} \mathrm{C}$, the damage of sandstone is mainly affected by water. Due to the Stefan effect of water [48], water exerts resistance to rock cracks, impedes the expansion of cracks, and thus improves rock strength. After reaching the peak value, with the increase of water bath temperature, the failure of sandstone is mainly affected by the temperature, and the microcracks in sandstone specimens gradually expand, which leads to the decrease of deformation resistance and elastic modulus of the specimens. The elastic modulus of the specimen has a quadratic function relationship with the water bath temperature, as shown in equation (6), and the fitting curve is shown in Figure 9:

$$
\begin{cases}E_{T 1}=-0.0397 T^{2}+4.284 T-54.141,25^{\circ} \mathrm{C} \sim 45^{\circ} \mathrm{C}, & R^{2}=0.9938 \\ E_{T 2}=0.0025 T^{2}-1.0393 T+99.292,45^{\circ} \mathrm{C} \sim 95^{\circ} \mathrm{C}, & R^{2}=0.9869\end{cases}
$$

where $E_{T 1}$ and $E_{T 2}$ are the dynamic elastic modulus $(\mathrm{GPa})$ of sandstone specimen after water bath.

\subsection{Analysis of the Relationship between Different Water Bath} Temperatures and Average Strain Rates. After the water bath, the average strain rate of sandstone varies with water bath temperature, as shown in Figure 10.
As can be seen from Figure 10, the average strain rate decreases in a quadratic parabola with the temperature increasing from $25^{\circ} \mathrm{C}$ to $45^{\circ} \mathrm{C}$. From $45^{\circ} \mathrm{C}$ to $95^{\circ} \mathrm{C}$, the average strain rate increases in a quadratic parabola with the increase of temperature. As shown in equation (7), the fitting curve is shown in Figure 10:

$$
\begin{cases}\dot{\varepsilon}_{T 1}=0.0233 T^{2}-2.1702 T+74.905,25^{\circ} \mathrm{C} \sim 45^{\circ} \mathrm{C}, & R^{2}=0.9959 \\ \dot{\varepsilon}_{T 2}=-0.0004 T^{2}+0.5051 T+3.5677,45^{\circ} \mathrm{C} \sim 95^{\circ} \mathrm{C}, & R^{2}=0.9935\end{cases}
$$

where $\dot{\varepsilon}_{T 1}$ and $\dot{\varepsilon}_{T 2}$ are the mean strain rate of sandstone specimen after water bath action, $\mathrm{s}-1$.

4.5. Failure Mode Analysis of Specimens. After experiencing different water bath temperatures, the failure modes of sandstone specimens SHPB under impact compression are shown in Figure 11.

As can be seen from Figure 11, under the same impact pressure, with the increase of water bath temperature, the damage degree of the specimen gradually decreases. When the temperature of the water bath was $25^{\circ} \mathrm{C} \sim 45^{\circ} \mathrm{C}$, the failure modes of specimens were large-scale flaking failure and axial splitting failure. When the water bath temperature was between $50^{\circ} \mathrm{C}$ and $95^{\circ} \mathrm{C}$, the failure mode of the specimen was side spalling failure. When the temperature reaches $95^{\circ} \mathrm{C}$, the damage degree of the specimen is small, and only a crack is formed on the side. To analyze the reasons, before the water bath temperature was $45^{\circ} \mathrm{C}$, the specimen expanded slightly under the joint action of temperature and water. Under the action of the microexpansion force, the internal microcracks of the specimen were closed, thus 


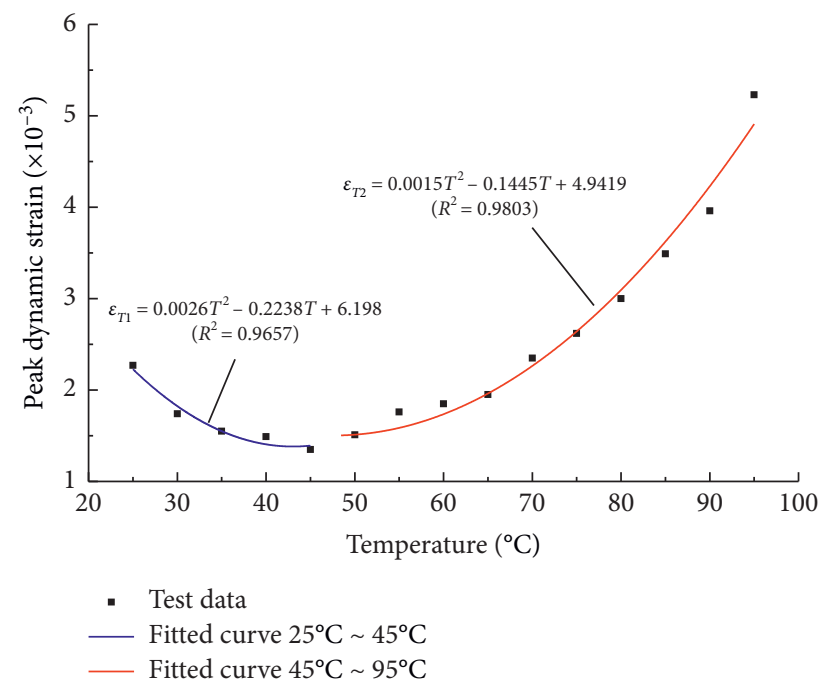

FIGURE 8: Fitting curve between water bath temperature and dynamic peak strain.

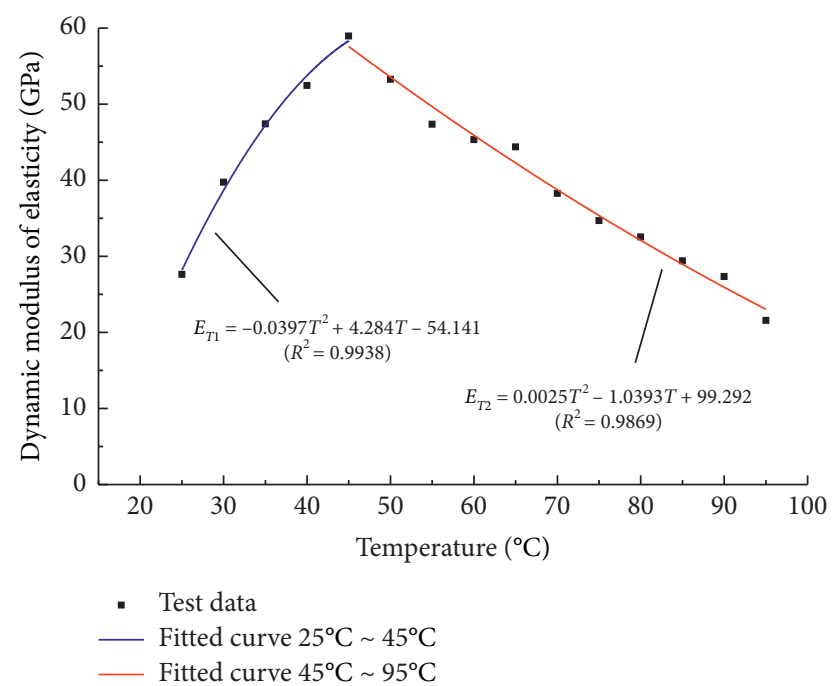

FIgURE 9: Fitting curve of water bath temperature and dynamic elastic modulus change law.

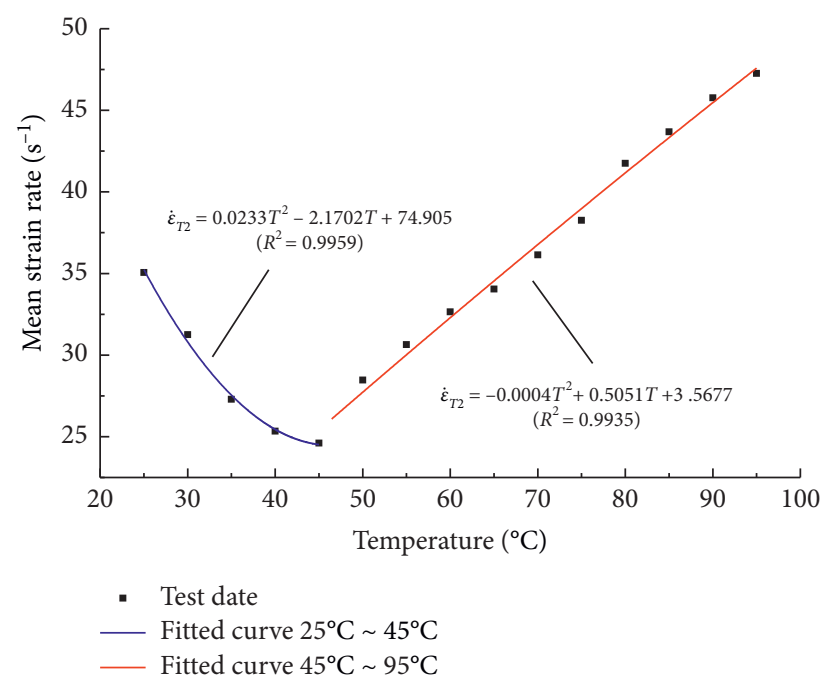

FIGURE 10: Fitting curve of change law between peak stress and average strain rate. 


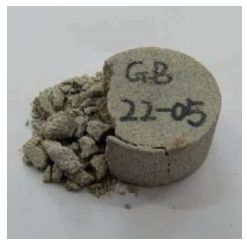

(a)

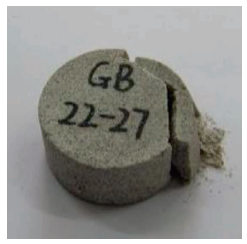

(f)

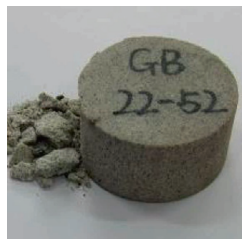

(k)

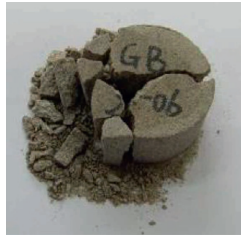

(b)

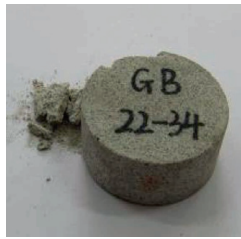

(g)

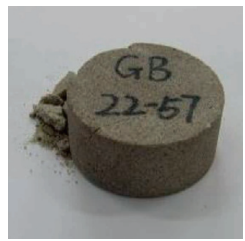

(1)

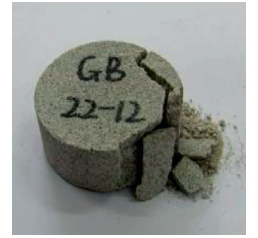

(c)

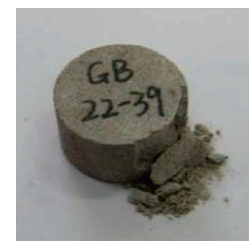

(h)

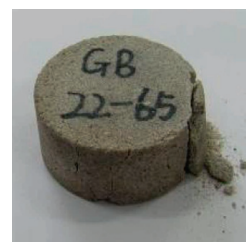

(m)

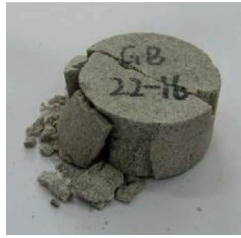

(d)

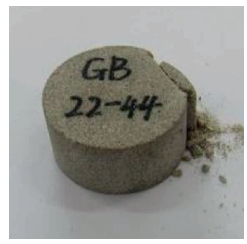

(i)

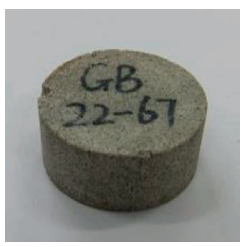

(n)

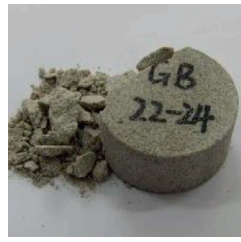

(e)

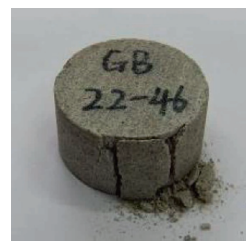

(j)

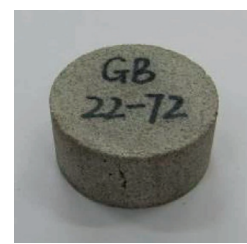

(o)

FIgURE 11: Dynamic compression failure modes of sandstone specimens with different water bath temperatures. (a) $25^{\circ} \mathrm{C}$. (b) $30^{\circ} \mathrm{C}$. (c) $35^{\circ} \mathrm{C}$. (d) $40^{\circ} \mathrm{C}$. (e) $45^{\circ} \mathrm{C}$. (f) $50^{\circ} \mathrm{C}$. (g) $55^{\circ} \mathrm{C}$. (h) $60^{\circ} \mathrm{C}$. (i) $65^{\circ} \mathrm{C}$. (j) $70^{\circ} \mathrm{C}$. (k) $75^{\circ} \mathrm{C}$. (l) $80^{\circ} \mathrm{C}$. (m) $85^{\circ} \mathrm{C}$. (n) $90^{\circ} \mathrm{C}$. (o) $95^{\circ} \mathrm{C}$.

making the specimen compact, the compressive strength of the specimen also increased, and the damage degree of the specimen gradually decreased. When the bath temperature was larger than $45^{\circ} \mathrm{C}$, more water was absorbed by sandstone specimen with the increase of temperature, resulting in the increase of Stefan effects. Therefore, it was more different for crack propagation of specimen under dynamic loading, and the specimen damage decreased gradually. In summary, the dynamic failure characteristics of water bath sandstone correspond to the strength characteristics.

\section{Conclusion}

(1) The sandstone at $25^{\circ} \mathrm{C} \sim 95^{\circ} \mathrm{C}$ is basically grayishwhite, and the surface particles of the specimen at $25^{\circ} \mathrm{C} \sim 45^{\circ} \mathrm{C}$ are compact. After $45^{\circ} \mathrm{C}$, the surface particle gap of the specimen is obvious, and the water absorption rate of the sandstone also gradually increases. The volumetric expansion rate, water absorption rate, and density increase rate of the specimens increased in a quadratic function relationship with the water bath temperature and increased slowly from $25^{\circ} \mathrm{C}$ to $45^{\circ} \mathrm{C}$, but rapidly from $45^{\circ} \mathrm{C}$ to $95^{\circ} \mathrm{C}$. After a $95^{\circ} \mathrm{C}$ water bath, the maximum increase rates of specimen volume and density were $0.94 \%$ and $2.47 \%$, respectively.

(2) The peak stress strength of the specimen increases in a quadratic function with the increase of water bath temperature. The rate of increase is small from $25^{\circ} \mathrm{C}$ to $45^{\circ} \mathrm{C}$ but large from $45^{\circ} \mathrm{C}$ to $95^{\circ} \mathrm{C}$. The dynamic peak strain of the specimen decreases first and then increases with the increase of water bath temperature, which is a quadratic function with the water bath temperature. The dynamic peak strain of the specimen is the minimum when the water bath temperature is $45^{\circ} \mathrm{C}$. The dynamic modulus of the specimen first increased and then decreased with the increase of the water bath temperature, which showed a quadratic function relationship with the water bath temperature. When the water bath temperature was $45^{\circ} \mathrm{C}$, the dynamic modulus reached the maximum. The average strain rate of the specimen decreases first and then increases with the increase of water bath temperature.

(3) The change of dynamic failure characteristics of the specimen corresponds to its strength characteristics. The fracture degree of the specimen under impact compression gradually decreases with the increase of water bath temperature. Because of the Stefan effect of water, the crack propagation of sandstone is hindered and the dynamic mechanical properties of sandstone are changed. When the temperature is $95^{\circ} \mathrm{C}$, the fracture degree of the specimen is the least, which appears as a crack on the side.

\section{Data Availability}

The data used to support the findings of this study are available from the corresponding author upon request.

\section{Conflicts of Interest}

The authors declare that there are no conflicts of interest regarding the publication of this paper. 


\section{Acknowledgments}

This research received financial supports from the National Natural Science Foundation of China (nos. 52074005, 52074006, and 51674008), Anhui Provincial Natural Science Foundation (no. 1808085ME134), and Anhui Postdoctoral Science Foundation (no. 2015B058). Thanks are due to the State Key Laboratory of Mining Response and Disaster Prevention and Control in Deep Coal Mine, Engineering Research Center of Underground Mine Construction, Ministry of Education, and Anhui University of Science and Technology, for providing the experiment conditions.

\section{References}

[1] M. C. He and P. Y. Guo, "Deep rock mass thermodynamic effect and temperature control measures," Chinese Journal of Rock Mechanics and Engineering, vol. 32, no. 12, pp. 23772393, 2013, in Chinese.

[2] M. C. He, H. P. Xie, and S. P. Peng, "Research on rock mechanics of deep mining," Chinese Journal of Rock Mechanics and Engineering, vol. 16, pp. 2803-2813, 2005, in Chinese.

[3] N. Qin, Q. Ge, Z. H. Liang, J. Sun, and Y. Wang, "Experimental study on macro/micro damage of sandstone caused by high temperature and prediction of uniaxial strength by BP neural network," Journal of Experimental Mechanics, vol. 36, no. 1, pp. 105-113, 2021, in Chinese.

[4] X. X. Yu, X. Z. Li, Y. Wu, M. Liu, and L. Deng, "Experimental study on change of physical and mechanical properties of limestone after high temperature," Yangtze River, vol. 51, no. 11, pp. 192-202, 2020, in Chinese.

[5] A. B. Jin, S. L. Wang, Y. D. Wei, H. Sun, and L.-c. Wei, "Effect of different cooling conditions on physical and mechanical properties of high-temperature sandstone," Rock and Soil Mechanics, vol. 41, no. 11, pp. 3531-3539, 2020, in Chinese.

[6] Y. C. Wu and L. Wang, "Experimental study on physicomechanical properties of granite after high temperature," Journal of Central South University, vol. 51, no. 1, pp. 193-203, 2020, in Chinese.

[7] B. Rohan, K. P. Sathis, and K. P. Samir, "Effects of hightemperature heating and cryogenic quenching on the physicomechanical properties of limestone," SN Applied Sciences, vol. 2, no. 10, pp. 478-483, 2020.

[8] X. Yu, G. Li, and Z. Chen, "Variation of uniaxial compressive strength for tight sandstone heating," Science Technology and Engineering, vol. 19, no. 32, pp. 133-138, 2019.

[9] C. D. Su, C. S. Song, and F. Q. Su, "Deformation intensity and acoustic emission characteristics of hard coal sample under uniaxial compression after high temperature," Journal of China Coal Society, vol. 45, no. 2, pp. 613-625, 2020, in Chinese.

[10] L. Y. Wei, G. L. Li, H. J. Su, H. Jing, and T. Zhang, "Experimental study on static and dynamic mechanical properties of anthracite after high temperature heating," Chinese Journal of Rock Mechanics and Engineering, vol. 36, no. 11, pp. 2712-2719, 2017, in Chinese.

[11] L. Chen, X. L. Xu, and Y. H. Xu, "Effect of temperature and loading rate on mechanical properties of rock," Journal of Guangxi University, vol. 41, no. 1, pp. 170-177, 2016, in Chinese.

[12] Q. Ping, M. J. Wu, and P. Yuan, "Experimental study on dynamic mechanical properties of high temperature sandstone under impact loads," Chinese Journal of Rock Mechanics and Engineering, vol. 38, no. 4, pp. 782-792, 2019, in Chinese.

[13] Q. Ping, C. L. Zhang, H. J. Sun, and X. Han, "Dynamic mechanical properties and energy dissipation analysis of sandstone after high temperature cycling," Shock and Vibration, vol. 2020, Article ID 8848595, 11 pages, 2020.

[14] Q. Ping, C. L. Zhang, H. P. Su, and H. Zhang, "Experimental study on dynamic mechanical properties and energy evolution characteristics of limestone specimens subjected to high temperature," Advances in Civil Engineering, vol. 2020, Article ID 8875568, 12 pages, 2020.

[15] Q. Ping, H. P. Su, and D. D. Ma, "Experimental study on physical and dynamic mechanical properties of limestone after different high temperature treatment," Rock and Soil Mechanics, vol. 42, no. 4, pp. 1-12, 2021, in Chinese.

[16] Y. Xu, K. Wang, and B. B. Shao, "Effect of temperature and load on dynamic mechanical properties and cracks of sandstone," Engineering Blasting, vol. 26, no. 4, pp. 17-22, 2020.

[17] R. R. Zhang, "Test and analysis of dynamic mechanics and damage characteristics of deep sandstone after different temperatures," Chinese Journal of Rock Mechanics and Engineering, vol. 37, no. S2, pp. 3879-3890, 2018, in Chinese.

[18] T. F. Chen, J. Y. Xu, S. Liu, P. Wang, and X.-Y. Fang, "Experimental study on dynamic mechanical properties of posthigh-temperature sandstone," Explosion and Shock Waves, vol. 34, no. 2, pp. 195-201, 2014.

[19] S. Liu and J. Y. Xu, "Effect of high temperature on dynamic compressive mechanical properties of granite," Journal of Vibration and Shock, vol. 33, no. 4, pp. 195-198, 2014.

[20] S. Q. Yang, W. L. Tian, and J. P. Dong, "Experimental study on failure mechanical properties of two grain granites subjected to high temperature," Chinese Journal of Geotechnical Engineering, vol. 43, no. 2, pp. 281-289, 2021, in Chinese.

[21] X. S. Xie, H. S. Chen, X. H. Xiao et al., "Microstructural characteristics and softening mechanism of red-bed soft rock under water-rock coupling," Journal of Engineering Geology, vol. 27, no. 5, pp. 966-972, 2019.

[22] G. Liu, Y. M. Li, and F. K. Xiao, "Study on failure mechanics behavior and damage evolution law of yellow sandstone under uniaxial triaxial and pore water action," Chinese Journal of Rock Mechanics and Engineering, vol. 38, no. S2, pp. 35323544, 2019, in Chinese.

[23] T. Z. Duan and Y. P. Ren, "Study on uniaxial compression mechanical properties of sandstone with different moisture content and wave velocity method," Coal Geology \& Exploration, vol. 47, no. 4, pp. 153-158, 2019.

[24] Y. B. Zhang, P. Liang, L. Sun et al., "Spectral characteristics of $\mathrm{AE}$ in the process of saturated granite fracture under uniaxial compression," Rock and Soil Mechanics, vol. 40, no. 7, pp. 2497-2506, 2019, in Chinese.

[25] J. Fang, Q. L. Yao, and W. N. Wang, "Experimental study on damage characteristics of siltstone under water action," Journal of China Coal Society, vol. 43, no. S2, pp. 412-419, 2018.

[26] J. Y. Teng, J. X. Tang, and Y. N. Zhang, "Damage process and characteristics of layered water-bearing shale under uniaxial compression," Rock and Soil Mechanics, vol. 38, no. 6, pp. 1629-1638, 2017, in Chinese.

[27] C. D. Su, Y. N. Sun, Z. H. Zhang et al., "On the effect of watersaturated state on failure energy of sandstone from coal seam roof subjected to uniaxial compression," Experimental Mechanics, vol. 32, no. 2, pp. 223-231, 2017, in Chinese. 
[28] Y. Y. Zhang, Microscopic Dynamics Mechanism of Deep Shale under Water-Rock Interaction, China University of Petroleum, Beijing, China, 2019.

[29] J. J. Fu, Z. D. Dong, Y. S. Yang, and H. Yi, "Evolution characteristics of mechanical parameters for sandstone under different water-rock interaction," Journal of Shenyang University of Technology, vol. 42, no. 3, pp. 350-354, 2020, in Chinese.

[30] Y. Yang, L. Mei, H. Liu et al., "Study on infrared radiation characteristics of siltstone after process of different temperature soaking," China Mining Industry, vol. 26, no. 6, pp. 149-153, 2017, in Chinese.

[31] L. S. Gao, Y. Xu, B. B. Wu, and S. Wang, "Dynamic compression strength of thermal damaged Fangshan marble on dry and saturated conditions," Chinese Journal of Rock Mechanics and Engineering, vol. 37, no. S2, pp. 3826-3833, 2018, in Chinese.

[32] G. Y. Wang, R. Yu, D. F. Ma et al., "Comparative study on dynamic tensile and compressive strength of the saturated fine sandstone," Chinese Journal of High Pressure Physics, vol. 34, no. 4, pp. 49-58, 2020, in Chinese.

[33] J. P. Zhao, M. H. Wang, and Y. H. Zhao, "Influence of moisture content on dynamic tensile strength of sandstone," Gold Science and Technology, vol. 27, no. 2, pp. 216-222, 2019.

[34] Z. L. Zhou, X. Cai, J. Zhou, and R. Cheng, "Mechanical properties of saturated sandstone under different loading rates," Chinese Journal of Rock Mechanics and Engineering, vol. 37, no. S2, pp. 4069-4075, 2018, in Chinese.

[35] F. J. Chu, D. W. Liu, M. Tao, and H.-D. Peng, "Dynamic response of sandstones with different water contents based on SHPB," Journal of Engineering Science, vol. 39, no. 12, pp. 1783-1790, 2017.

[36] H. Y. Wang, J. X. Xu, P. Wang et al., "A study of dynamic compressive strength and microscopic mechanism on waterbearing rock," Journal of Air Force Engineering University (Natural Science Edition), vol. 17, no. 4, pp. 107-111, 2016.

[37] P. Y. Guo, B. H. Bai, S. Chen, C. Shi, and H. Du, "Effect of temperature and moisture content on thermal properties of sandstone," Chinese Journal of Rock Mechanics and Engineering, vol. 36, no. S2, pp. 3910-3914, 2017, in Chinese.

[38] L. Yu, H. W. Peng, Y. Zhang et al., "Effects of the number of water-heat cycles on the physical and mechanical properties of granite," Science Technology and Engineering, vol. 21, no. 2, pp. 703-713, 2021.

[39] K. Hashiba and K. Fukui, "Effect of water on the deformation and failure of rock in uniaxial tension," Rock Mechanics and Rock Engineering, vol. 48, no. 5, pp. 1751-1761, 2015.

[40] L. N. Y. Wong and M. C. Jong, "Water saturation effects on the Brazilian tensile strength of gypsum and assessment of cracking processes using high-speed video," Rock Mechanics and Rock Engineering, vol. 47, no. 4, pp. 1103-1115, 2014.

[41] H. Karakul and R. Ulusay, "Empirical correlations for predicting strength properties of rocks from P-wave velocity under different degrees of saturation," Rock Mechanics and Rock Engineering, vol. 46, no. 5, pp. 981-999, 2013.

[42] H. M. An, T. S. Zeng, Z. H. Zhang, and L. Lei, "Experimental study of the rock mechanism under coupled high temperatures and dynamic loads," Advances in Civil Engineering, vol. 2020, Article ID 8866621, 19 pages, 2020.

[43] M. Wen, J. Y. Xu, H. Y. Wang, X. Y. Fang, and G. H. Zheng, "Fractography analysis of sandstone failure under low temperature-dynamic loading coupling effects," Rock Mechanics and Rock Engineering, vol. 36, no. 2, 2017.
[44] Z. L. Wang, H. Shi, and J. G. Wang, "Mechanical behavior and damage constitutive model of granite under coupling of temperature and dynamic loading," Rock Mechanics and Rock Engineering, vol. 51, no. 10, pp. 3045-3059, 2018.

[45] National Standards Compilation Group of the People's Republic of China, Method for Determination of Physical and Mechanical Properties of Coal and Rock, Standards Press of China, Beijing, China, 2010.

[46] Chinese Society for Rock Mechanics \& Engineering, “T/ CSRME 001-2019 technical specification for testing method of rock dynamic properties [EB/OL]," 2019, http://www.ttbz.org. $\mathrm{cn} /$ Home/Show/10253.

[47] L. L. Wang, Stress Wave Foundation, National Defense Industry Press, Beijing, China, 2010.

[48] Z. Dan and Q. B. Li, "An explanation for rate effect of concrete strength based on fracture toughness including free water viscosity," Engineering Fracture Mechanics, vol. 71, no. 16-17, pp. 2319-2327, 2004. 